\title{
Between initial familiarity and future use - a case of Collocated Collaborative Writing
}

\author{
Susanne Bødker and Anna Maria Polli \\ Department of Computer Science, Aarhus University, Denmark \\ \{bodker, ampo\}@cs.au.dk
}

\begin{abstract}
This paper reports on a design experiment in an art gallery, where we explored visitor practices of commenting on art, and how they were shaped in interaction with a newly designed collocated, collaborative writing technology. In particular we investigate what potentials previous practices carry with them that may affect early use and further development of use. We base our analyses on interviews in the art gallery and on socio-cultural theories of artefactmediated learning and collaboration. The analyses help identify three forms of collaborative writing, which are placed in the space between future use possibilities and initial familiarity based on everyday practices. These forms met and at times collided in a space where the actual use was shaped. We furthermore look back on initial assumptions made in design regarding a productive collaborative writing style, and confront these with the three above forms of practice. The initial familiarity leads to two different early practices that get in the way of each other, and the collaborative writing idea. They point instead towards a discursive sharing of individual feelings, a different kind of past experiences than anticipated in design.
\end{abstract}

Keywords: Collocated collaborative installation, early use, developmental process of use, initial familiarity, future use

\section{Introduction}

In this paper we take our starting point in an explorative use setting where a collocated collaborative writing platform was set up to support people in sharing their interpretations of art pieces in an art gallery. The ideas were

- to support contributions from people when they were in the art gallery

- to give access to a format of contributions that was open to be shaped by the audience/contributors without previous introduction

- to give access to the contributions of others so as to produce a shared text, inspired by the way Wikipedia gives access to sharing entries

- while also bridging the divide between the artist who produces the artwork, the curator who traditionally produces an authoritative curative text, and the 
audience who discuss among themselves, in particular in small groups that visit the art gallery together. This was somewhat pretentiously framed as 'democratic curation' even though it may be a direct replacement of a curational text.

There is a wide body of work related to the use of Wikipedia-like technologies in museums and art galleries, and we don't want to discuss neither museum technologies in general, nor the potential for using Wikipedia in such settings. (Macdonald, 2007) gives an excellent overview of art institutions, the curatorial process, and the deployment of IT in museums in general. (Thom-Santelli et al., 2010) discuss the development of art expertise and the connected feeling of ownership in a museum gallery, where novices and experts together were collaboratively tagging the exhibition. (Galani and Chalmers, 2002) evaluate a prototyping experiment where physically and virtually co-located visitors collaborate. (Ciolfi et al., 2008) discuss two technological installations where visitors were engaged in reflection, discussion and debate around the exhibits. The idea that a Wikipedia-like technology may move curation towards more openness and democracy is unfolded in the context of museums by (Phillips, 2013).

In the current paper, we are interested in what happened when visitors got introduced to the new technological artifact, more than we are concerned with longer-term evaluation or wider issues of the usefulness of such technologies in art galleries, where temporary exhibitions are shown.

The paper introduces the study and the use situation further, introducing a sociocultural theoretical framing and methods. It moves on from there to analyze the data and bring out findings. The socio-cultural framing fundamentally helps understand human practices, how they are shaped in interaction with artifact ecologies, and how they carry with them potentials for further development.

\section{Set-Up and Deployment}

The research project (LAA-Local Area Artwork) was deployed at the art gallery Kunsthal Aarhus, a venue for contemporary art. We had in total three meetings with the artists and their curator to introduce the LAA idea, to test and discuss the prototype. Additionally we had four separate preparation meetings with the staff of the art gallery. After a discussion with the management and the staff from the gallery, an exhibition by the local artists Afgang13, in May 2013 was selected. The exhibition, entitled New G, was a traditional exhibition including paintings, sculptures and installations. This art gallery usually presents curated exhibitions, where artists have produced their art pieces and put them to show in the art gallery and together with the curator describe the artwork and its relation to the exhibition. The art gallery and the artists allowed us to experiment with the text often accompanying the artwork. The idea was to let people write a collaborative interpretation of the artwork on our digital panels (see Figure 1 Left), which were positioned next to the art piece. We studied the use of installation and how the audience would write a text together during the exhibition period (Figure 1 Right). 


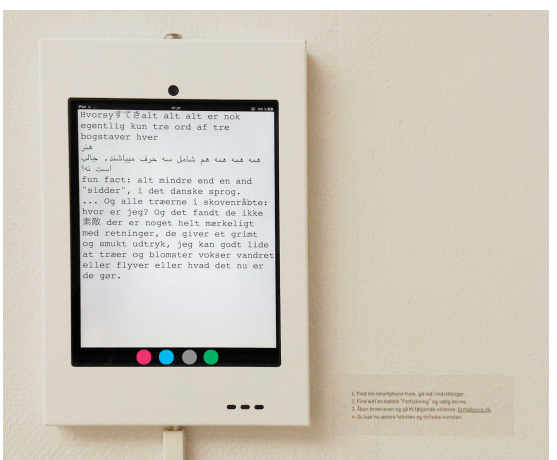

Figure 1: One digital panel with a small label next to it providing connection instructions.

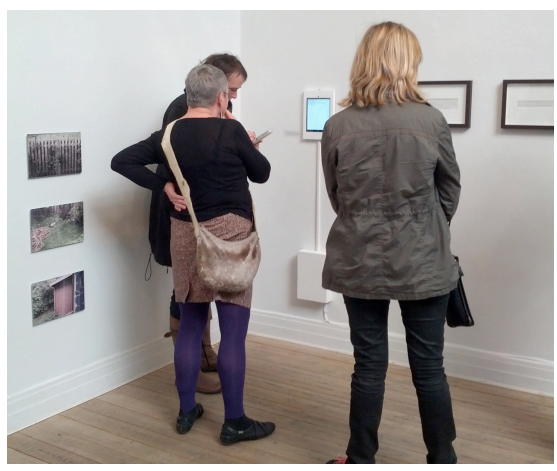

Figure 2: Visitors interacting with the panels through their personal devices to write comments.

Our research instrument consisted of six iPads or, as we call them, panels, which were deployed in the three rooms of the exhibition. In this setting visitors, artists, curators and the staff were invited to engage with or through our panels. The artists, the curators and the staff were familiar with the project as we discussed them in length together. The visitors were briefed to the research project and the new technology when entering the art gallery. Visitors we offered to interact with the text on the panels through their own smartphones, requiring no installation, since a web page was automatically launched when the user/smartphone was in the vicinity of a panel. While standing in front of the artwork and the display, people could edit and write new text (Figure 2). When connected to the Wi-Fi, and upon opening a web-browser, they were automatically redirected to the editable version of the digital panel. We assumed that there was very little learning needed, since a small label next to the panels provided connection instructions (Figure 1).

At the start of the exhibition, the panels were deliberately left blank to provoke and not limit the audience in their writings/usages. Neither did the curators provide any initial texts or interpretations about the artworks.

We applied the notion of Wikipedia into our design, to seek Wikipedia-style collaboration and participation with the artworks. For this purpose, we created these panels as shared surfaces where collocated visitors and people coming after each other could write joint interpretations. To emphasize the collocated use, the text was liveupdated on the digital panel, and dots at the bottom of the panel showed how many people were actively editing (Figure 1). The newly written text would appear in these respective colors to create awareness of the same-time editing of several people. All the written text was limited to the visible area of the one-page display, and no scrolling was enabled on the panel. When the display was full, the users got a notification on their phone to delete or edit what previously had been written. For details in respect to the implementation of the installation see (Korn and Klokmose, 2012, Polli et al., 2013, Bødker et al., In Preparation). As we return to, we carried out a number of empirical investigations throughout this exhibition period. 


\section{Theoretical framing}

In analyzing the material, we draw from socio-cultural research. This approach fundamentally aims at understanding human practices, how they are shaped in interaction with artifacts, and how they carry with them potentials for further development.

With our analytical perspective human beings are situated in a web of activities and ecologies of technological artifacts (cf. Bødker and Klokmose, 2011). Accordingly, we are concerned with the ecology of artifacts into which new technological designs, such as the LAA, get placed and how such a technological design changes the artifact ecology. In addition, we are concerned with the activities from which users draw their experiences. (Bødker and Christiansen, 1997) seek inspiration in (Ricoeur, 1990), who is talking about the space of experience and the horizon of expectation. Ricoeur sees expectations always in the light of experience, and experience always from particular expectations. Accordingly, we are looking back at the quite early experiences that people had with the panels, how they relate these experiences to other artifacts and to past practices; what expectations they have when it comes to the usefulness of the panels in art exhibitions, and what understandings they evoke in explaining this.

In understanding how people talk about relating past experiences to expectations of future use, we seek inspiration from Bakhtin, ((Wertsch, 1998) p.54 and (Bødker and Christiansen, 2012)), who talk about language and how a word is first somebody else's and then, when being picked up, first is half someone else's half one's own. It becomes one's own only when populated with one's own intentions, one's "accent", when one appropriates it. In continuation of socio-cultural theory we focus on the use of a new artifact and the way the users talk about this develop together. We are interested in the problems of introducing the LAA panels in art curation and discussions, as well as what potentials it holds, in particular for the visitors.

(Engeström, 1987) points out that change processes are not fully predictable: When a new artifact is brought into use, its use cannot be predicted. Neither is use static and unchangeable. Hence, we need to understand better the relationships between the future use, and part practices and artifacts (see also (Bødker and Klokmose, 2012)). (Bødker and Christiansen, 2012) describe appropriation through anticipation, initial familiarity, development of repertoires of routines and the development of new forms of use. This perspective allows us to understand development of human practices in the meeting with what is in one way or another different from what the learners already are capable of, or the concept of the zone of proximal development which has come to mean the possible future practices, or developmental potentials, spanned out in confronting existing practice with other ways of doing similar things (Bertelsen and Bødker, 2003). Our understanding of the LAA panels are as springboards (Engeström, 1987) for such a development because, when placed into the art gallery they confront existing practices, trigger among users an initial familiarity that is based on these former practices, while they point ahead to future use possibilities (Bardram and Bertelsen, 1995).

What is interesting for this paper is to understand what users identify as initially familiar, what existing practices they draw on, what explicit or implicit "help" (or 
hindrances) they get from the artifact in forming their initial use, and how existing practices and new uses can somehow constitute the core potential for future use. This happens on the background of the network of actors and activities surrounding the meeting of the user with the artifact (Figure 3). Again we will use the socio-cultural understanding of networks of activities (Bødker and Klokmose, 2011) as activities that are interconnected and mediated by artifacts, always carried out by people. Are there any kinds of understanding that helps people across from initial familiarity to a consolidated use? Do some of the different kinds of initial familiarity clash? And to what extent do they help or hinder users in getting towards their own conception of future use?

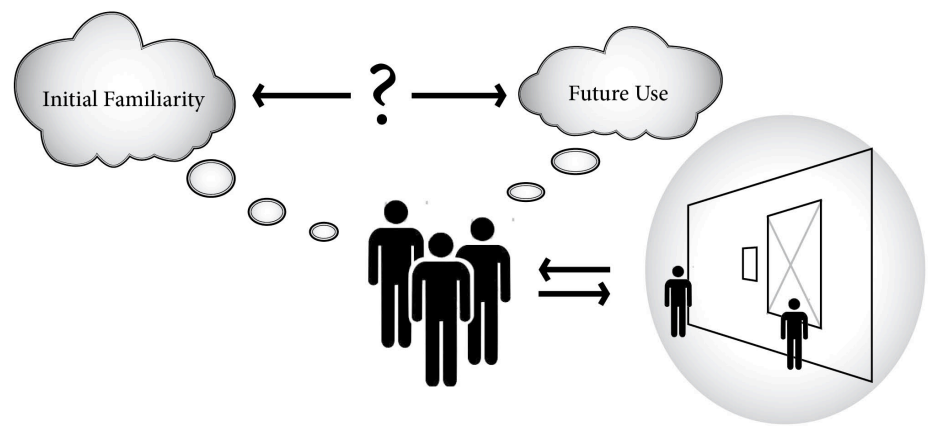

Figure 3 The model: The relation between the exhibition visitors as we interview them, and the actual meeting with the technology in the exhibition, as well as the relation between the initial familiarity that they experience in the exhibition activating past practices, and the future use that they come to understand, or expect in the Ricoeurian sense. The analysis is focused on how the LAA mediates communication in the art gallery, and hence the space between initial familiarity and future use.

\section{$4 \quad$ Empirical method}

The project was deployed at the art gallery for over one month, a period of an exhibition, and accordingly our study was limited in time. Over this period we carried out several kinds of activity that we will not go into further here: we e.g. carried out panel discussions with artists, curators and staff from the art gallery and we asked visitors to fill out short questionnaires. In focus in this paper are 13 exit interviews on-site with 19 visitors and our log of different user activities where we recorded the history of written, edited and deleted text by participants over the whole exhibition period.

The semi-structured exit interviews were carried out with visitors, who were interviewed individually and in pairs (see Table 1). The interviews lasted from 20 to 45 minutes. A variety of people were invited to the interviews, both those who engaged with our installation and those who were with them, which included families, couples, and individuals. The interviewee's age was broad and ranged from around 15 to 65 .

The 13 interviews were transcribed, and the transcripts were used as a basis for the bottom-up analysis, where the quotes were extracted and categorized. Since we 
worked with interview data, this analysis primarily helped us understand how people talk about their use, triggered by the actual use of the panels. We triangulated these analyses with the above theoretical understanding of learnable artifacts and with the $\log$ data of how people actually used the panels.

\begin{tabular}{l|ll}
\hline & Interviewee's Description & Initials \\
\hline Interview \#1 & A couple (woman and man) in their 20s & $(1 \mathrm{M})$ \& (1C) \\
Interview \#2 & Woman in her mid 60s, visiting alone & $(2)$ \\
Interview \#3 & Man in his early 40s, visiting alone & $(3)$ \\
Interview \#4 & A couple (woman and man) in their end-20s & $(4 \mathrm{D}) \&(4 \mathrm{~L})$ \\
Interview \#5 & Woman, teenager, visiting with her parents & $(5)$ \\
Interview \#6 & Man in his end 30s, visiting alone & $(6)$ \\
Interview \#7 & Daughter (early 20s) and father (late 50s) & $(7 \mathrm{~A}) \&(7 \mathrm{P})$ \\
Interview \#8 & A couple (woman and man) in their early 30s & $(8 \mathrm{~K}) \&(8 \mathrm{E})$ \\
Interview \#9 & Man in his mid 50s, visiting with his family & $(9)$ \\
Interview \#10 & Siblings (woman and man) in their mid 20s & $(10 \mathrm{~V}) \&(10 \mathrm{M})$ \\
Interview \#11 & Man in his early 50s, visiting with a friend & $(11)$ \\
Interview \#12 & A couple (woman and man) in their mid 30s & $(12 \mathrm{M}) \&(12 \mathrm{C})$ \\
Interview \#13 & Woman in her early 30s, visiting alone & $(13)$ \\
\hline
\end{tabular}

Table 1. List of interviews.

Since the exit interviews were made after brief visits in the exhibition, the data mainly allowed us to dig deeper into what initial familiarity the artifact seemed to activate in the visitors, and what future uses they imagined based on these very early encounters with the LAA. In addition the interviews gave some indications as to the very early learning that happened in and outside use, and the conditions that people thought they encountered for activating former practices in possible future use.

\section{$5 \quad$ Findings and Analyses}

In the following section we present our findings and analysis. After setting the scene by describing the network of people and their activities as well as the challenges of formal and informal learning in LAA we turn to future uses. These are grouped under three headings, and emphasize the various kinds of use of our research instrument: In the interviews, participants were indicating diverse understandings of future use of the technology, and we are trying to identify the diversity of these. More than a handful of types of usages were talked about in the interviews, and we will further look into three of those to understand specifically the collaborative side of possible future uses. After introducing each of the usages, another important question will be answered: Where do these future uses come from? What influences the interviewees to develop these expectations of particular future uses? We use people's expression of initial familiarity to address how particular images of use have come into existence as expectation of future use for the users. We found in our analysis many ways in which interviewees talk about what in LAA they recognized (as what) and on which they 
immediately draw their initial use. In fact we find a long list of overlapping artifacts and practices. These practices are in several ways the starting point for the learning and we are interested to learn how they are brought into a new context and are made useful in the interaction with the LAA.

\subsection{Network of communities and activities}

An art exhibition is the home of an intrinsic network of activities many of which go into the shaping of the art experience for the visitors: Art pieces have been selected by curators with some kind of idea and sense of quality in mind. In an art gallery like Kunsthal Aarhus, the physical layout of the building plays an important role for how the exhibition can be brought together. The artists at the same time have produced the art pieces from some sort of idea. There may be a dialogue between the curators and the artists regarding the process and exhibition. Traditionally, the curator (and not e.g. the artist) gets to do an interpretation of the art piece that gets conveyed to the spectators in (roughly) an A4 size text. The curator or curators also arrange the exhibition. The audience, the spectators, willingly or unwillingly, gets to see the result, to walk the exhibition, to engage with the artwork, as well as with the curations (which may also include catalogs etc.). Some of the audience may know what the exhibition is about while others don't. Some people come in groups, while others come alone. Some of these people are indeed more knowledgeable than others, and some are quite happy to share this knowledge.

It is into this network that we brought LAA with the hypothesis that it could extend the engagement among visitors while getting rid of or lessening the authoritative voice of curator in the exhibition, much in the same way as Wikipedia can be seen as a platform for encyclopedia without appointed experts.

\subsection{Getting started with LAA}

LAA is indeed based on the idea that very little learning or introduction is needed outside of actual use. As a matter of fact it has been based on three basic ideas, one being that people can interact with the panels on their own devices with zero install (Bødker et al., In Preparation) and direct access on the phone/device to the text on the panels; that basically LAA offers mainly a blank sheet of paper where it is legitimate to write anything, and finally that a bit of very minimal instruction could be given by the art gallery staff at the entrance of the gallery (when purchasing tickets). The question to be asked is obviously whether this sufficed? In the following sections we discuss what kinds of assumptions people made regarding use and in those sections we return to how they then draw upon earlier experiences in use (and when they talk about it).

The question that we look into much further in the following is which elements of LAA that may or may not support the collaboration and learning among visitors in the art gallery? 


\subsection{Future use as Sharing reflections}

In this section we will elaborate on the first future use possibility Sharing Reflections, which is talked about several times throughout the interviews. People talked about a kind of use, where they would share their experiences about the art works. "I think it's positive just that people reflect on things they see" (6). This was a novel experience for visitors in an art gallery, and triggered people to think ahead. They were talking about our installation as: "a possibility to make a comment about it (artwork), and then people who come another day, or later today could read it, that you could actually give your own point of view and someone will read it" $(1 \mathrm{M})$. Those participants also wrote with the purpose of making others reflect from a different perspective: "it also gives like an experience to the audience coming later and you write and they read that and you can affect their look upon the art piece" (8 R2). Others were strengthening this possible use in the making by indicating: "someone is writing short messages and it gives you an association, it could be nice to comment to that" (9) or "it's also nice to read what other people write, because you look at the work of art and then you have an opinion and you read the comments and [...] you adjust your own view on the artwork because you know what some other people think" (7 R1). People read others comments to confront and adjust their point of view on the art piece. Figure 3, illustrates (from the log files) how participants share their reflections about one artwork, after adjusting and relating their comments to the previous written ones.

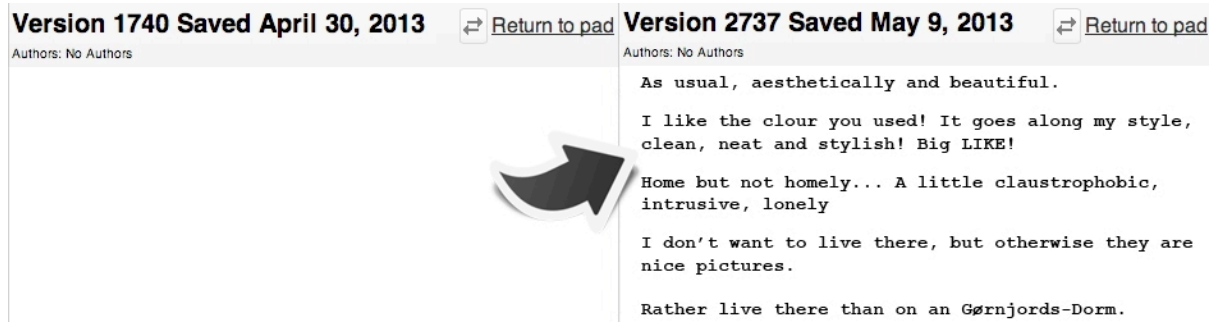

Figure 3. Screenshots from the transformation on the panels, from a blank screen to an active screen with several separate shared reflections (translated).

These interviewees see people writing their comments or reflections about the art piece on the panels, on the one hand to contribute to this interpretation panel, on the other hand to stimulate others coming later to think differently about an artwork. This again inspires others that read those, and perhaps adjust their view on the artwork accordingly. This socially recursive process of sharing reflections was detected in the interviewees' responses throughout the deployment period of our installation. People described this phenomenon as: “a communication" (13).

The idea of sharing their reflections may be to engage other visitors to think about the art from different perspectives. People explained they: "commented on each others comments" (4L) as a kind of meta-reflection or a reflection actually happening at two levels: First as a way of engaging among visitors that are present at the same time in the exhibition. Second in an indirect way, a communication of unknown users, where previous users have left comments on the panels that later users pick up on. 
Even though people were not present at the same time, many of the interviewees embraced the idea of having such reflective dialogues with other visitors about an artwork through the panels. Interviewees embraced the idea of following up on other's comments, which not only changed their ways of thinking about the art piece, but also in particular motivated them, to respond to these comments. When the interviewer was asked about their use: "so you followed up on the previous comment that was written there?" (11), one participant responded: "yeah, we did that. Hopefully in a good way, I just wrote a short comment to him" (11). This quote illustrates the reflective cycle quite well: "I interacted with him and he interacted with the sculpture and interacted with me too, at the same time" (11), or "I thought about activating the audience instead of just the curator creates the direction and write something" (4D).

Sharing reflections is in consort with the idea of LAA that the curatorial writing switches from the hands of the curator to: "every day people, (who are) writing what they think about it." (1C). This indicates that this future use possibility points towards a social and more democratic interactivity, where various people are writing an interpretation and not just the curator. The traditional curatorial text is unchanged, but through involving visitors the text evolves over time within the exhibition period: "you can also get, like a new piece of art out of it, because when people write what they feel when they see it, and you have to delete something, then it changes over time." (1C) This future use represents a further support to the design of LAA. As well as the matter of bringing people back to local places correlates to our idea of LAA. "I would not mind, because I have a notion that art critics is going to flow away, since people have the opportunity to comment more through the net" (11). This points out that people move away from traditional understandings of what happens in and around art galleries and towards something more interactive that seems to compare to various forms of commenting on the Internet.

Moving on to initial familiarity, we turn to four practices, which can be identified as previous understandings and actions that people brought into consideration for their initial use; or recognized as initial familiarity. These four, are indeed not the only ones that we identified, as we see below, but they are the four that most directly relate to Sharing reflections as future use.

\section{Familiarity with curation texts}

People know and compare the texts on the LAA panels with traditional art catalogues: "a lot of time when you look at art, it's just like browsing through a catalogue"(4A). They recognize that curators produce texts for art exhibitions, such as: "there is someone who knows art, who describes this piece" (1M).

\section{Familiarity with getting involved and art interpretation}

People interested in arts are familiar with: "usually, when I go to an exhibition, I always interpret" (3). Therefore people consider this practice as iterative cycle of communication: "I interacted with him (the artist), he interacted with the sculpture and he interacted with me too, at the same time" (11) or "it's how to get a dialogue with an artist, that's the only way to talk to him to have a dialogue, for this it can be used" (2). 


\section{Familiarity with off-line art discussions}

"I have a friend who sent a text and sometimes he was going and passing by a shop in New York and then he was on the net and he wrote to us" (9). This indicates that people do not necessarily carry out art discussion in the local place, but also: "it's like when you get used to it and use the internet, instead of reading a magazine and then you normally read the comments and when you then read it then in a printed magazine, you like the comments like that extra layer" (1M).

\section{Familiarity with the chat-room}

"I like the idea of that like open chat-room thing, that sounds like a really good idea actually" (10M) or "because more kind of a creative dialogue to have with strangers, so it's fun" (4D). Or the following comment by (11): "yeah I just stated: think about it, to the next person (...) that's all short, you don't have to write a long newspaper article, you just can make it short and then again you interact with people (interviewer: yes, and then you give the next guy to think about) (laughing) hopefully, that's interacting right?"

People refer back to these four practices, when they are talking about the future use of sharing reflections, yet there is no direct way from these to the notion of sharing reflections: Classical curation texts (see Familiarity 1) are not about sharing reflections, yet people seem to recognize and even appreciate the input from somebody understanding art. Some of the people who are interested in art also share art discussions (Familiarity 3) and see themselves in a sort of hermeneutic loop with the artist and the art piece (Familiarity 2). In comparison with these three, the chat-room (Familiarity 4) comes out of a quite different space of experience, that has little to do with art specifically, yet is quite well reflected in the use of the panels in Figure 3. The three first of these (Familiarity 1-3) are different in that (Familiarity 1) points to the role of the consumer of professional art texts whereas 2 and 3 are about sharing within the audience. Where the initial familiarities 1-3 could just as well point to a future use that would be closer to a Wikipedia-style text production, it is no 4 that helps understand that the kind of sharing of reflections that the visitors are after, is different from Wikipedia: an actual dialogue between the visitors.

This same structure will be now used to analyse two more future uses that were identified through the interviews, before we move on to address the bigger picture when these conceptions of future use meet.

\subsection{Future Use as Guestbook}

The second notion of future use relates to the guestbook metaphor. The design idea of the blank white screen of the panels evoked several ideas of what future uses may be like, such as applying the style of writing like in a guestbook, as when our participants were explaining about other visitors: "they use it like a guest book" (1C). Some people used the installation like a guestbook or Foursquare check-in to say they were there. In Figure 4 there are two evidences for writing as in a guestbook, on the left we have an indication of a greetings style and to the right we spotted initials from one of the authors, where we have the evidence that one of our interviewees stated: "On the first one I wrote my name, on the others I didn't (laughing)" (6). 


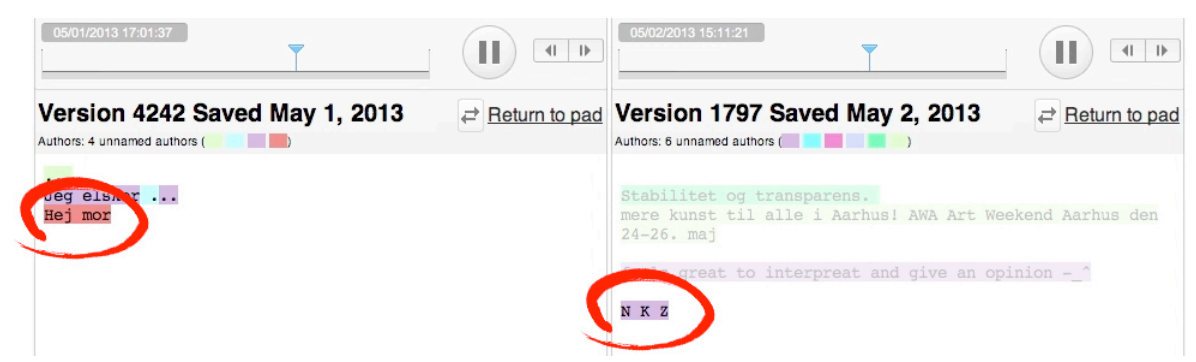

Figure 4. Screenshots indicating two characteristics of a guestbook, left: greetings ("Hi Mom"), right: Initials of the author.

When our interviewees talk about this style of possible future use it reflects a previous practice where people come to museums or other semi-public spaces and there is a guestbook available. Some people write comments in this about their visit and to state their presence.

\section{Familiarity with tagging "I was here" and guest books:}

The analogy with guest books was drawn e.g. by an interviewee: "I think it depends a lot on what people write, because if you use it just like a guestbook, just to write HI $H I^{\prime}$ " $(1 \mathrm{M})$, and several other interviewees also mention how the comments left by other audience is almost like tags: "so it was not like a discussion, it was more like "I was here, I liked it"'" (6).

The classical guestbook here meets both Foursquare check-ins and perhaps even more graffiti-like tagging in this future use. In this way, the practice of leaving a brief note to way "I was here" is understood and recognized by many visitors, through not without frustration, as we return to, as when (6) points out that it was not like a discussion. More straight forward the interviewees worry about clutter, and somehow the interviewees seem to worry about this guestbook style as a potential waste of good writing space.

We return to how this future use further collides with the other future uses in section 5.7.

\subsection{Future Use as Facebook wall}

Some interviewees pointed towards another future use possibility, of writing in the style as on the Facebook wall, where they state it is: "interesting that when there is a text, and then have a comment to the text and then like have a string, where there was a commented text" (9). Another indication that people see a possible future use of Facebook originates from this comment: "each piece of art that is on Facebook, then you could just have a wall, and then you know people write on the wall of the page and then you know, people comment on each other, then you can see the history start" (12C). Further images of future use developed out of that openness, such as making use of existing platforms: "it could be a great future, if you could take up the battle (of the discussion) on Twitter or on an online forum [...], because you have two opposing opinion of the artwork and could get into a nice discussion" (4L). In Figure 5 
we illustrate the separately written interpretation of an artwork, where people write comments like on Facebook, separated with blank lines.

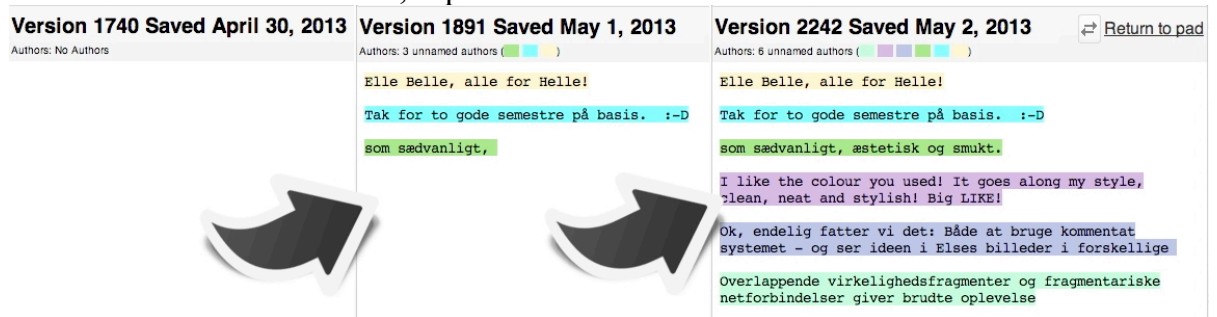

Figure 5. Screenshots from a discussion about the artwork, where separate comments remind of a style of writing like on Facebook (note the mixed languages).

In this future use, the written text relates to the artwork, and the comments are meaningfully related to each other. While e.g. 4L indicates a future use that is wider than simply the well-known Facebook wall, this wall style is nonetheless quite directly appropriated by the visitors in writing on the LAA panels as can be seen in Fig. 5. They keep a strict distinction between the comments as they are familiar with from Facebook, and all in all this use shows a very direct link to the initial familiarity (6, below) of seeing the LAA panels as a version of the Facebook wall.

\section{Familiarity with Facebook}

Facebook often gets mentioned as an analogy from which people draw their experiences: "then you could just have a wall, and then people write on the wall of the page and then you know, people comment on each other, then you can see the history start, something more, this was really like, this really looked like a white board, right?" (13C) or "yeah I mean, I post on Facebook, I write emails, I guess (...) I was writing on a website using my phone, so my phone was just my keyboard" (12M). Further details are added e.g. by another interviewee: "you post everything on Facebook, on Twitter, it's just people have comments on everything, so why not art?" (4L) and "I like to maybe have it a bit more organized, so there are people that do it and anonymous or you can write names but maybe also like write a time or just 'like' something (...) so you can see when it's a new one who write, because that kind of confused me, I didn't really get when sometimes people make like (...) a separation with the line or something" (10V).

On Facebook (or Twitter) comments are produced by individuals alone, and in this sense they share with art pieces and classical curation texts a "Do-Not-Touch" atmosphere. As discussed in (Bødker et al., In Preparation), people hesitate to delete the texts of others, which creates collisions with the one page format proposed in LAA. Hence, the acted out initial familiarity/future use in the gallery runs into problems when the screen fills up. This causes confusion, but apparently now enough for people to change their expectations for this kind of future use of LAA.

In the next section we look into how the early practices identified in the art gallery seem to be sustainable in the journey towards a future use. 


\subsection{The sustainability of early practices}

In the process of adopting a technology, people are dependent on technologies and practices that are well known to them, such as discussions on Facebook walls and discussions of art, as we have pointed to above. The questions that one may raise, however, given our theoretical framing is the extend to which these forms of initial familiarity also help users take the first steps towards more solid shared practices of collaborative use?

In the interviews, people themselves e.g. questioned the sustainability of the tagging or guestbook practices: "People didn't really write so much, so it was not like a discussion, it was more like "I was here, I liked it"" (6) or, "I think there is a problem, that a lot of the comments are not about the art, it is more like: Hi, hi I am using this. But I think it would be very nice, if it was like comments focusing on the piece of art" (1M).

The Facebook practices seem more consistent in that they are already being used quite extensively in the art gallery (see Section 5.5). It seems that the early practices of e.g. texting or Facebook walls are more recognizable than that of e.g. shared editing such as in Wikipedia, which does not get mentioned in the interviews (despite the initial design idea), or than the practices of sharing reflections. Since people are familiar with these types of platforms or environments, such as Facebook or writing in a guestbook, they tend to draw upon these practices. People that applied the guestbook on the digital panel may have different daily practices, than the participants that were thinking of sharing their reflections on the panels. However, the above analysis indicates that sharing reflections in the long run may be limited by these writing styles, and hence that the limitations of guestbook and Facebook writing styles may in the longer perspective limit the possibilities of embracing this vision of future use.

Beyond the sustainability of initial practices we will look into this minefield of clashing uses in further detail in Section 5.7.

\subsection{The meeting of the future uses in the art gallery}

We have identified three kinds of future uses, and six elements of initial familiarity that together were elements of shaping how people met the LAA panels and started one or more forms of collaboration mediated through the LAA panels. This space of mediation is, however, not just one where all forms of initial familiarity, and future use live equally smoothly alongside one another, it is more to the contrary.

First of all, the two future uses of sharing reflections and of guestbook tagging seemed ill at ease with each other: "I could imagine if you can have a long discussion or something, if there is space enough? It could be fun and, I don't know, my impression was that it was rather...I didn't really read a lot, it was my impression that people didn't really write so much, so it was not like a discussion, it was more like "I was here, I liked it" (6). This future use-"Hi, I liked it"-was sensed by some people as a hindrance, since it interfered with their expectations of more real communication.

Subsequently, some interviewees felt demotivated from noting down further thoughts about the artwork: "I think it depends a lot on what people write, because if 
you use it just like a guest book, just to write "HI HI", then you won't get so much out of it. [...] But I think that advantage comes when more people are more focused, on what they think of this piece of art, because that's what interesting for other people to read and to discuss more specific about each art piece" (1M).

Others describe the same matter more specifically: "there are different outcomes depending on how people use it, because if they use it like a guestbook, it is not that giving, and then, yeah, you can get like a new interpretation of the artwork, because it is every day people, writing what they think about it" (1C). Subsequently the use of the guestbook writing style, illustrates a barrier that is preventive to sharing interpretations, and for the Facebook wall format discussions as well.

While perhaps more fragmented the Facebook future use seems more at ease with the sharing reflections, and it may actually be seen as one specific way of sharing reflections; a way where each statement is brief and left alone, even though it can be commented on.

In several ways the potential future uses and initially familiar kinds of use, are clashing with each other. Striking examples of contradicting uses exist across the Guestbook style, Facebook style and Sharing reflections use. And while one seems more obvious in the short term (Facebook wall) it does not necessary provide the shortest path, or even a path at all, to the vision of sharing reflections. The various kinds of initial familiarity confuse the participants and therefore eliminate each other and prohibit most likely a long lasting practice, turning the LAA into the battleground of various practices.

However, also confusion and disruptions were revealed, which are analogous to Bakhtin's resistance and the artefact talking back: "well actually, I didn't understand exactly what it was, I thought because in summer I read some explanation about the art pieces (...) so maybe I thought it is just information about the art on those iPads, but then I saw like some other comments...." (1M). These establishing uses are not just supportive for users to get started, they are confusing as well.

As discussed above, this may be preventive of developing reflections that are shared in a different sense than stating opinions that are being put in the open to be commented on. However, it is not clear from the interviews how far people imagine to be able to move when it comes to sharing reflections: Are they imagining a more genuine discussion, one-to-one or several visitors together?

Beyond the future uses that we identified from the interviews are the ones that we didn't see. Specifically, as we mentioned in the introduction, the design idea of a Wikipedia-like style of sharing an interpretation of the art piece is missing. It is missing both in what people actually did on the panels, and in how the interviewees talked about future practices and initial familiarity. Nobody mentions Wikipedia as an initial familiarity; a known object; a writing/editing style to depend on. LAA does not get picked up and used for actively editing and deleting others' comments so as to produce one coherent interpretation. Nobody mentions it as a future practice, and even though sharing reflections comes close it is still different: Where Wikipedia emphasizes a product or a shared object/outcome, the interviewees are more concerned with sharing their individual feelings and thoughts, so as to align those with the feelings and thoughts of others, and with the actual art piece. 


\section{Discussion}

In this paper we have worked primarily with interview data, which have been connected also with $\log$ data from the panels. For this analysis, we got the most helpful data from the interviews, though we are going to continue working with the content of the log-files. There are a number of challenges with this approach some of which relate to making empirical studies of technologies in open and sporadic activities such as art galleries ((Ciolfi et al., 2008), (Brown et al., 2011)). When it comes to addressing future use possibilities, in particular and how people perceive of them based on very early use experiences, we find that interviews provide a better basis than e.g. observations of use. This is because neither the horizon of expectation nor the space of experience for that matter, are easily tapped into through observation, in particular when the actual interaction is brief and sporadic (Careful analysis of some amount of actual video data of use could give indications regarding initial familiarity and future use ideas). The two elements are largely linguistic, and we have treated them that way. The experiences, however are at the same time not as individual, retrospective or longitudinal as e.g. those considered by (McCarthy and Wright, 2004). For this reason, we find that there is room for better analytic methods in this space, and we see our work here as only the beginning.

In CSCW there has, in particular in the earlier years, been an extensive focus on collaborative writing. We have not spend much of our attention here on these writings, because there are many ways in which our work is quite far away from these many studies of focused co-writing in productive writing practices. As a matter of fact with our conclusion it seems to make more sense to compare our empirical material with other genres of (on-line) communication, be they email or chat-fora. A more systematic attempt at this, however, pertains to our future work.

The final comment goes to the design idea of the open design. Overall the assumption was that the blank editable sheet would lead some sort of shared something, perhaps even a productive co-production. Even though, designwise, we sat out to expect the unexpected, the analyses seem to point out that even this open format makes assumptions about future use, and that beyond this openness there is a next layer where it is quite difficult to make assumptions about which existing practices users may lend from when recognizing the design in initial familiarity, and when thinking about what this new design may be in future use.

\section{Conclusion}

We have identified three profound, yet contradictory, future uses and seen how they are mirrored in various forms of initial familiarity. Our users want to try to share reflections, but among them destroy this communication through scattered non-related guestbook comments. Two radically different ways of use get in the way of each other and seems to make the path towards a discursive sharing of individual feelings and thoughts less clear and perhaps impossible. 
We designed an open installation, meaning there was little initial learning and introduction expected. Our analyses show that users nonetheless bring to the table, past experiences that strongly influence the possibilities of future use. This is inevitable and cannot as such be anticipated through better design, even though the theoretical framing and analytic method presented and applied in this helps drawing attention to the specific possibilities and hindrances in the specific context.

\section{References}

1. Bardram, J.E., Bertelsen, O.W., 1995. Supporting the development of transparent interaction, in: Human-Computer Interaction. Springer, pp. 79-90.

2. Bertelsen, O.W., Bødker, S., 2003. Activity theory. HCI Models Theor. Framew. Multidiscip. Sci. 291-324.

3. Bødker, S., Christiansen, E., 2012. Poetry in motion: appropriation of the world of apps, in: Proceedings of the 30th European Conference on Cognitive Ergonomics. pp. 78-84.

4. Bødker, S., Klokmose, C.N., 2011. The Human-Artifact Model: An Activity Theoretical Approach to Artifact Ecologies. Human-Computer Interact. 26, 315-371.

5. Bødker, S., Klokmose, C.N., 2012. Dynamics in Artifact Ecologies, in: Proceedings of the 7th Nordic Conference on Human-Computer Interaction: Making Sense Through Design, NordiCHI '12. ACM, New York, NY, USA, pp. 448-457.

6. Bødker, S., Klokmose, C.N., Korn, M., Polli, AM., In Preparation. Introducing participatory IT in local, shared discussions.

7. Brown, B., Reeves, S., Sherwood, S., 2011. Into the wild: challenges and opportunities for field trial methods, in: Proceedings of the SIGCHI Conference on Human Factors in Computing Systems, CHI '11. ACM, New York, NY, USA, pp. 1657-1666.

8. Ciolfi, L., Bannon, L.J., Fernström, M., 2008. Including Visitor Contributions in Cultural Heritage Installations: Designing for Participation. Mus. Manag. Curatorship 23, 353-365.

9. Engeström, Y., 1987. Learning by Expanding. An Activity-theoretical approach to developmental research.

10. Galani, A., Chalmers, M., 2002. Can You See Me? Exploring Co-Visiting between Physical and Virtual Visitors.

11. Korn, M., Klokmose, C.N., 2012. Putting "Local" Back into Public Wifi Hotspots, in: Proceedings of the 2012 ACM Conference on Ubiquitous Computing, UbiComp '12. ACM, New York, NY, USA, pp. 800-801.

12. Macdonald, S., 2007. Interconnecting: museum visiting and exhibition design. CoDesign 3, 149-162.

13. McCarthy, J., Wright, P., 2004. Technology as experience. interactions 11, 42-43.

14. Phillips, L.B., 2013. The Temple and the Bazaar: Wikipedia as a Platform for Open Authority in Museums. Curator Mus. J. 56, 219-235.

15. Polli, AM., Korn, M., Nylandsted Klokmose, C., 2013. Local area artworks: collaborative art interpretation on-site, in: Proceedings of the 2013 ACM Conference on Pervasive and Ubiquitous Computing Adjunct Publication. pp. 79-82.

16. Ricoeur, P., 1990. Time and narrative. 3. University of Chicago Press.

17. Thom-Santelli, J., Cosley, D., Gay, G., 2010. What do you know?: experts, novices and territoriality in collaborative systems, in: Proceedings of the SIGCHI Conference on Human Factors in Computing Systems, CHI '10. ACM, New York, NY, USA, pp. 16851694.

18. Wertsch, J.V., 1998. Mind as action. Oxford University Press, New York, NY, US. 